\title{
Three Dimensions of the Sociality of Action
}

Some Reflections based on the Cultural Psychology of Michael Tomasello and Sociological Pragmatism

Frithjof Nungesser

\section{(2) OpenEdition}

\section{Journals}

Electronic version

URL: http://journals.openedition.org/ejpap/782

DOI: $10.4000 /$ ejpap.782

ISSN: 2036-4091

\section{Publisher}

Associazione Pragma

Electronic reference

Frithjof Nungesser, «Three Dimensions of the Sociality of Action », European Journal of Pragmatism and American Philosophy [Online], IV - 1 | 2012, Online since 23 July 2012, connection on 03 May 2019 URL : http://journals.openedition.org/ejpap/782 ; DOI : 10.4000/ejpap.782

This text was automatically generated on 3 May 2019.

\section{cc)}

Author retains copyright and grants the European Journal of Pragmatism and American Philosophy right of first publication with the work simultaneously licensed under a Creative Commons AttributionNonCommercial-NoDerivatives 4.0 International License. 


\section{Three Dimensions of the Sociality of Action}

Some Reflections based on the Cultural Psychology of Michael Tomasello and Sociological Pragmatism

Frithjof Nungesser

\section{AUTHOR'S NOTE}

I would like to thank all participants of the SIAS Summer Institute "Action Theory in Philosophy and the Social Sciences" (2009/10) hosted by Hans Joas and Robert Pippin for many helpful discussions as well as the SIAS program for supporting this workshop. For helpful suggestions, I am also grateful to Matthias Jung, Stephan Moebius, VerenaSusanna Nungesser and Patrick Wöhrle. Finally, I would like thank Caitlin Ahern for proofreading the manuscript.

\section{Introduction: The Sociality of Action - Extrinsic or Intrinsic?}

How exactly are our individual actions related to sociality? This is one of the crucial questions in social theory and diverse answers have been proposed in social philosophy and the social sciences. In this paper, I will argue for an action theoretical perspective that conceives of agency and sociality as intrinsically related. I will do so by drawing on two distinct strands of cultural and social theory: the sociological pragmatism of Charles Horton Cooley and especially George Herbert Mead, and the cognitive cultural psychology of Michael Tomasello.

2 By embracing an intrinsic approach, I will reject the competing extrinsic conception that cuts human action into halves by distinguishing between two separate types of action: individual action on the one hand, and social action on the other hand. For example, for 
most of contemporary psychological social psychologists, ${ }^{1}$ social actions are directed towards social objects while other types of action are not. Such an understanding of 'social action' would deprive all actions dealing with nonsocial objects of their social dimension. Alternatively, one could claim - following Weber - that "we shall speak of 'action' insofar as the acting individual attaches a subjective meaning to his behavior - be it overt or covert, omission or acquiescence. Action is 'social' insofar as its subjective meaning takes account of the behavior of others and is thereby oriented in its course" (Weber 2007 [1922]: 4; see also 22ff.). In this view, actions related to nonsocial objects may also be regarded as social actions because their 'subjective meaning' takes into account the behavior of others. Yet, while Weber's classical definition may allow for a more adequate perspective on social action, it still fails to acknowledge crucial aspects of the sociality of action. Perhaps most dramatically, in his writings on methodology or action theory Weber never raises the question to what extent action must be seen as social per se or whether sociality is constitutive for agency. Consequently, Weber thinks of social action as just one specific type of action. ${ }^{2}$

3 Perhaps surprisingly, a similar problem can be found in the work of another founding figure of sociology. In Durkheim's methodological and anthropological remarks, individual action is not social by nature. Rather, the individual actor is depicted as intrinsically instinct-driven, insatiable and egocentric. "It is not human nature which can assign the variable limits necessary to our needs. They are thus unlimited so far as they depend on the individual alone. Irrespective of any external regulatory force, our capacity for feeling is in itself an insatiable and bottomless abyss" (Durkheim 1979 [1897]: 247). By "external force" Durkheim means, of course, society that shapes the individual and sets the limits. Yet, at least in the early Durkheim, even the socially well adapted individual is split into two: asocial and egoistic on its individual side, social and altruistic on its collective side (e.g. Durkheim 2004 [1893]: 253f.).

4 Given this admittedly crude sketch, it seems that most social scientists - not only 'methodological individualists' such as Weber or (psychological) social psychologists, but also 'methodological holists' such as Durkheim - conceptualize the connection between action and sociality as extrinsic. ${ }^{3}$ Social processes are thought to be something external and separable from the individual and its actions. In contrast, 'intrinsicalists' highlight "the irreducible sociality behind all individual acts" (Joas 1996: 189). In this perspective, sociality is a constitutive condition for and essential dimension of human action. Consequently, the goal is not foremost to distinguish between different forms of individual and social action. Rather, the question is how the individual's ability to act selfreflexively and autonomously can be explained on the basis of its irreducible embeddedness in intersubjective processes.

5 In this paper I want to contribute to this theoretical tradition by outlining three dimensions of the sociality of action based on the work of Michael Tomasello as well as sociological pragmatism. By distinguishing between a cognitive, motivational and cultural dimension of the sociality of action I will show why the relation between human action and sociality can only be understood if we conceptualize it as intrinsic. Since the work of Mead or Cooley will be more or less familiar to most readers within philosophy or social theory, the focus will mainly be on Tomasello. ${ }^{4}$ Only later he will be seconded by the pragmatists.

6 I will start with an introductory characterization of Tomasello's approach to cognitive psychology (II). Based on this approach, I will heuristically identify three dimensions of 
the sociality of action in Tomasello's work (III). Chapter IV then compares these results with the central tenets of sociological pragmatism. As a result, it will hopefully become clear that, generally speaking, social theory can substantially benefit from crossdisciplinary exchange, especially with certain strands within cognitive and cultural psychology. More specifically, cognitive scientists like Tomasello can help us to reformulate pragmatist social theory against the background of recent findings in the human sciences. By doing this, we can adhere to the original transdisciplinary claim of pragmatist thought that has long been neglected in sociological theory. ${ }^{5}$ Yet, in the end, it is this transdisciplinary perspective that constitutes the fundamental importance of pragmatism for the social sciences.

\section{A Short Characterization of Tomasello's Approach to Cognitive Psychology}

7 Tomasello's basic question is why human life is impregnated by culture in such an extraordinary way:

Human beings and only human beings cognize the world in ways leading to the creation and use of natural languages, complex tools and technologies, mathematical symbols, graphic symbols from maps to art, and complicated social institutions such as governments and religions. The puzzle is that other primates have created none of these things even though some - the great apes - are as closely related to humans as horses to zebras, lions to tigers, rats are to mice. (Tomasello \& Rakoczy 2003: 121)

In order to solve this "puzzle" Tomasello has been conducting comparative experiments with human children and nonhuman primates. To understand why he is such a convinced "advocate of the comparative method" (Tomasello 2006: 507), one has to look back over a few decades.

9 Since the 1930s the debate on whether nonhuman primates have the capacity to acquire natural languages or other alleged human-specific faculties has been heated. In the 1930s the chimpanzee Gua was raised by Winthrop N. and Luella A. Kellog, disciples of Robert Yerkes, as though she were a human child in order to teach her to speak a language. Since then much ink has been spilled on the (supposed) language skills of Gua or other chimpanzees like Viki, Washoe, or Nim Chimpsky (cf. e.g. Terrace et al. 1979; Gardner \& Gardner 1989; Yule 2010: 16ff.). The debate is still ongoing. Yet, in Tomasello's view, two inferences can be drawn for certain. On the one hand, comparative analyses of the language skills of enculturated (i.e. human-raised) and mother-reared chimpanzees demonstrate the enormous impact of cultural processes during ontogeny (Tomasello 1999: 34-6). Enculturated chimpanzees show marked differences to their mother-reared conspecifics with regard to attentional, learning and language skills. For example, they are able to request desired items by using sign language and are capable of imitation learning (cf. Tomasello 2008: 246-56; Tomasello et al. 1993). On the other hand, it is obvious that enculturated apes, even after undergoing intensive training, "do not thereby turn into human beings" (Tomasello 1999: 35). Human-raised apes still show severe 'limitations.' Compared with human children they do not engage in the same way in "extended joint intentional interactions" and they lack decisive linguistic (esp. syntactic) competences (Tomasello 2008: 249-56). 
Tomasello's work derives two important conclusions from this extensive discussion. First, systematic research on the socio-cultural impact on human and nonhuman primate ontogeny is needed. Second, the human-specific cognitive and motivational infrastructure must be identified, which explains the substantial differences between humans and both enculturated and mother-reared nonhuman primates. By means of well-controlled comparative studies of the cognitive development of human children and (mother-reared as well as enculturated) great apes, both objectives can be pursued. This is why 'Developmental and Comparative Psychology' constitutes Tomasello's methodological 'silver bullet.'

In my own research group, we have chosen to approach these problems [= to explain human cooperation and culture; FN] via comparative studies of human children and their nearest primate relatives, especially chimpanzees. The hope is that in these somewhat simpler cases we may see things more clearly than is possible in the myriad complexities of adult human behavior and societies. (Tomasello 2009b: xvii)

11 One thing that can be seen "more clearly" in these comparative experiments is the intrinsically social and qualitatively new character of human cognition and action which, according to Tomasello, can be demonstrated most clearly by means of the simple act of pointing.

12 Tomasello states that "the majority of studies of nonhuman primate communication focus on their vocal displays." Thus, most of these studies do not look into gestures. Yet, while vocalizations in apes are "mostly unlearned, genetically fixed, emotionally urgent, involuntary, inflexible responses to evolutionary important events," gestures are "individually learned and flexibly produced communicative acts" (Tomasello 2008: 54). Hence, in order to study the influence of the socio-cultural environment during ontogeny, gestures are far more instructive research objects. This is why Tomasello considers the traditional focus on vocal displays to be "a huge mistake" (Tomasello 2008: 53).

Indeed, in comparative analyses, enculturated and mother-reared apes show marked differences with respect to their gestural behavior while no new vocalization skills emerge in this process. In the wild, great apes do not point - neither to show something to their conspecifics (declarative pointing) nor to share an experience with them (expressive pointing). Moreover, they do not even point in order to request something (imperative pointing). ${ }^{7}$ In contrast, enculturated primates point quite often. However, they do so only imperatively - and only when humans are present. They never point when interacting with conspecifics (Tomasello 2006; Tomasello 2008: 34ff.). In the following section I will illustrate why exactly these observations are of such crucial importance for social theory and action theory by distinguishing three dimensions of the sociality of action and cognition in Tomasello's work.

\section{Three Dimensions of the Sociality of Action in Tomasello}

\section{III. a) The Cognitive Dimension}

For Tomasello, it is the seemingly trivial act of pointing - and not the often invoked faculties of language or reason - that contains in itself the seeds of human culture. 
Pointing, so the argument goes, requires a species-specific form of social cognition, namely, the cognitive infrastructure of shared intentionality. This infrastructure, in turn, relies on several capacities. Individuals that share their intentions must be able to cognize triadic interactions. In order to understand a pointing gesture, I have to realize that someone is trying to direct my attention to a certain object. Imagine, for example, two friends on a hike in the Black Forest. Now, friend A is pointing en passant to a chestnut tree in order to please friend B. A knows that chestnuts are B's favorite trees. B understands A's pointing only because she knows that he knows that chestnuts are her favorite trees. In this example, B has to be able to cognize the relation between A's communicative intention (to draw her attention to the tree), his referential attention (the chestnut tree) and his social intention (his message: “Look! A chestnut tree - isn't that nice?").

The example shows that shared intentionality does not only presuppose 'triadic' cognition but also 'recursive mindreading' (A knows that B knows that A knows...). Without the recursiveness of human social cognition the constitution of a 'common ground' necessary for communication would not be possible (Tomasello 2008: 4ff.; 73-82). ${ }^{8}$ To speak of a common ground, however, implies two (or more) individuals acting in the same context. A common ground is not just all the things that are part of a given situation. Rather, it "is what is 'relevant' to the social interaction, that is, what each participant sees as relevant and knows that the other sees as relevant as well" (Tomasello 2008: 74). This is why Tomasello (and others) ${ }^{9}$ think of common ground as something that is shared. In our example, B knows that chestnuts are her favorite trees just as A knows that chestnuts are B's favorite trees. However, when it comes to communication the crucial point is that A and B know together that chestnuts are B's favorite trees. This means that A has to know that B knows that he knows that chestnuts are B's trees of choice and that B knows that A knows that she knows that he knows that chestnuts are her favorite trees. ${ }^{10}$ Without this shared common ground built on recursive mindreading, B would not understand A's pointing.

Compared with iconic signs such as facial expressions or pantomime, the understanding of indexical signs is more dependent on common ground. This is because in icons "more information is potentially in the gesture itself." Thus, "iconic gestures should be more effective than pointing, in many contexts, with strangers" (Tomasello 2008: 203). In a way, there is even greater dependence on shared ground when it comes to communicative conventions. More often than in indexical and (non-symbolic) ${ }^{11}$ iconic gesturing, the objects referred to in symbolic communication are absent and/or imperceptible by the senses. Also, in conventionalized communication, the (more or less) arbitrary signs are themselves part of the common ground. This also explains why, for Tomasello, language itself depends on these social cognitive skills (Tomasello 2008: 218). Moreover, gestures and language are interlocked phylogenetically as well as ontogenetically. Tomasello claims that in the development of spoken language there occurred/occurs a double-transition from pointing to demonstratives such as 'this' and 'that' and from iconic gestures to content words, e.g. nouns and verbs (Tomasello 2008: $324){ }^{12}$

17 Yet, language not only draws on human-specific socio-cognitive skills. It also has an enormous impact on the development of human cognition. This cultural aspect of human cognition and action will be discussed in more detail later (III. c). For the moment, the decisive insight is that, according to Tomasello, the simple act of pointing demonstrates 
that human beings - as opposed to nonhuman primates (e.g. Tomasello 2006: 509) always act in a shared cognitive space, which "takes people beyond their own egocentric perspective on things" (Tomasello 2008: 76). Consequently, the concept of shared intentionality does not primarily focus on 'parallel' attentions, knowledge, and intentions. Rather, the crucial point is that people who share their intentionality attend together, know together, and intend together. This is to say that they know that each of them knows of, attends to, and intends something. But they also always know that the other knows that they know of, attend to, and intend something, and vice versa. Thus, we always act within a space of shared representations, attentions, and intentions. Within this space, "in direct competition, shared common ground trumps individual personal relevance every time" (Tomasello 2008: 77). Yet, the anthropological account of the intrinsic sociality of cognition and action that can be formulated on the basis of Tomasello's work takes into account not only the cognitive infrastructure but also the motivational basis of action.

\section{III. b) The motivational dimension}

18 As shown above, nonhuman primates in their natural habitats do not point for each other, while their human-raised companions do so imperatively (but not declaratively or expressively). ${ }^{13}$ In this context, it is important to note that both mother-reared and enculturated apes are unable to understand pointing. Several experiments conducted by Tomasello and other primatologists over the last several years strongly support this claim. For example, Tomasello, Call, and Gluckman introduced apes to the so-called 'object choice task. ${ }^{14}$ In this game one human hid some food in one of three opaque containers. Later, another person tried to help the apes by pointing at the baited bucket. Although the primates knew from past experience about the helpfulness of this human and although they were "attentive and motivated," they chose at random. This holds true even when trained conspecifics, rather than humans, pointed at the box containing the food. However, the apes' failure to understand pointing is not based on their inability to follow the direction of the pointing gesture. In several experiments it became clear that nonhuman primates are quite talented in following pointing and gaze directions (Moll \& Tomasello 2007: 640). Accordingly, in the 'object choice task' the tested primates followed the deictic gesture of the experimenter to the baited container. This did not, however, influence their decision. Moreover, in another research design, which focused more on competition than on cooperation, these apes demonstrated their ability to understand intentional action. In order to obtain the food stored in a bucket, the experimenter had to reach through a hole in a plexiglass barrier (note that reaching looks quite similar to pointing). However, he did not get it because the bucket was out of reach. Later, his simian competitor had the opportunity to choose between the different buckets on the other side of the barrier. Importantly, in this design, she did so very successfully - in most cases she selected the container the experimenter had tried to reach before (Tomasello 2006: 508).

19 The increased use of competitive paradigms in the study of primate cognition over the last few years has demonstrated that apes are endowed with considerable abilities to represent the intuitions and perceptions of others (cf. Tomasello et al. 2003; Tomasello 2006; Call \& Tomasello 2008; Kaminski et al. 2008). For Tomasello these findings have constituted a serious challenge because until around the year 2003 one of his 
fundamental claims had been that "the overwhelming weight of empirical evidence suggests that only human beings understand conspecifics as intentional agents like the self" (Tomasello 1999: 6). Moreover, according to Tomasello's 'first theory,' other uniquely human forms of social cognition do follow automatically from this single basic cognitive difference..$^{15}$ For example, in this view, the understanding of others as not only intentional but mental agents is merely "a kind of "icing on the cake" - the "cake" of course being the capacity to understand the intentions of others (Tomasello \& Rakoczy 2003: 122). ${ }^{16}$

Given these recent findings, we must conclude that "understanding goals or intentions is not the same thing as understanding communicative intentions" (Tomasello 2006: 508). ${ }^{17}$ Thus, by observing their conspecifics and by guessing their intentions, chimpanzees and other nonhuman primates gather important environmental information. Yet, they do not understand that other beings may have the intention to draw their attention to some object. In other words, apes do not realize that the communicative behavior of other individuals may be conducted 'for them.' In contrast, human children start to point not only imperatively but also declaratively and expressively at around one year of age (Tomasello 2008: 135ff.). They do so without any instruction. Hence, for Tomasello, there seems to be an intrinsic drive in human children to express themselves, to share their experiences with others and to help other individuals (Tomasello 2008: 82-8) ${ }^{18}$ Around the same age, children also learn to understand all types of pointing. Consequently, at only 12 to 14 months of age, toddlers pursue and recognize what Tomasello, following Grice, calls "communicative intentions," that is, the kind of intention in which "you intend for [me to share attention to (X)]" (Tomasello 1999: 102).

However, human children are not only motivated by the desire to help and share when they point. They also have quite specific expectations regarding the appropriate reaction of others to their pointing. For example, Liszkowski et al. proved that 12-month-old infants were dissatisfied with the reaction to their declarative pointing when the adults only looked briefly at the object, showed no reaction or emoted positively without reference to the object. Only when the adults looked back and forth between the object and the child and expressed a positive reaction were the toddlers pleased (cf. Tomasello 2006: 511). ${ }^{19}$

According to Tomasello, from all of this evidence it follows that the simple act of pointing is representative of the intrinsic cooperative nature of human communication. Humans communicate out of the motives of sharing and helping (i.e. helping or being helped). And they verify whether their communicative act is understood. If necessary, humans repeat and - more importantly - reformulate their communicative acts. This seems to be another human-specific kind of behavior. It not only constitutes a showcase for the essentially cooperative nature of human communication but also draws attention to the necessary connection of cooperativeness with common ground. The ability to match one's message to others presupposes the faculty of recursive mindreading. Without this social cognitive skill, and thus, without a common ground, successful communication would be impossible or at least highly improbable.

Consequently, the intrinsic sociality of action does not only have a cognitive foundation (namely, shared intentionality) but also a motivational basis - the intrinsic social character of the human motivational structure. The close connectedness of these two aspects can also be studied with regard to their respective developmental chronologies (cf. Tomasello 2008: 135-67). On the one hand, the cognitive infrastructure of shared 
intentionality develops between the 9th and 12th month. Thus, it follows the understanding of individual intentions, which is the first key result of the 'nine-month revolution.' On the other hand, parts of the motivational structure seem to be in place quite early in ontogeny. Three-month-olds demand action (e.g. by ritualized crying), share emotions "in face-to-face dyadic exchanges" and engage in "a process of affective attunement in which infants and adults tune into the emotions of one another" (Tomasello 2008: 137). While infants are capable of imperative and expressive behavior even before the nine-month revolution, informative communication develops only after the goals and the knowledge of others can be understood. Accordingly, the demanding of action and the sharing of experiences by means of pointing begins only after the infrastructure of shared intentionality - and hence common ground - has developed. Conventionalized communicative gestures usually emerge around the 14th and 18th month. In almost every case a period of intensive pointing precedes symbolic communication.

Now, given the close connectedness of these two processes, the question needs to be asked whether there are substantial differences between humans and their nearest relatives in both dimensions. In other words: Would chimpanzees be able to engage in shared intentionality if they were motivated to help others and to share their experiences? Or would they be supportive and expressive if they could create common ground? Tomasello does not answer this question conclusively. On the one hand he argues that apes do not point because "(1) they do not have the motives to share experience with others or to help them by informing; and (2) they do not really know what is informationally new for others, and so what is worthy of their communicative efforts" (Tomasello 2006: 513). Yet, on the other hand, he writes that "[t]he main difference is motivational (with perhaps a cognitive dimension to this in the sense that infants may be motivated to do things that apes cannot even conceive)" (Tomasello 2006: 510; see also 517). While the first passage suggests that there are important dissimilarities between humans and other primates in both dimensions, the second quote grants a certain priority to the motivational aspect. In order to answer this question a far more fine-grained picture of anthropogenesis is needed. At the moment, a conclusive answer seems to be out of reach. Yet, at least conceptually, one can specify the motivational and cognitive features that allow for the intrinsic sociality of human cognition and action. What is more, this motivational and cognitive infrastructure is indispensable for explaining the cultural aspect of human cognition and action.

\section{III. c) The Cultural Dimension}

25 According to Tomasello, human cognition becomes more complex through cumulative cultural evolution..$^{20}$ This cumulative cultural process, also known as the 'ratchet effect,' presupposes 'sociogenesis' as well as reliable methods of cultural transmission. The term 'sociogenesis' is used by Tomasello to characterize those processes "in which something new is created through social interaction of two or more individuals in cooperative interaction, and indeed in many cases the new product could not have been invented by any of the individuals acting alone" (Tomasello 1999: 41). ${ }^{21}$ By "species-unique modes of cultural transmission" (Tomasello 1999: 4) Tomasello means processes of imitative learning and teaching. Taken together, these two processes allow for cumulative cultural evolution. In contrast, animals - including apes - fail to generate cumulative traditions. However, they do so not primarily because they lack the creative skills. Instead, it is the 
inability to preserve their innovative problem-solutions that prevents the emergence of a cumulative cultural history (Tomasello 1999: 5).

It will not come as a surprise that, in Tomasello's (current) theory, both sociogenesis and cumulative cultural learning are based on the described human-specific capacity of shared intentionality. On the one hand, sociogenesis is a form of cooperation. In order to cooperate with someone I have to understand that we have a common goal. Moreover, I have to recognize that the other person has a different perspective on the same problem and thus has a different role to play in order to reach the common goal. Finally, all individuals have to be motivated to collaborate in order to make sociogenesis happen. Thus, it quickly becomes clear that sociogenesis rests on the basis of shared intentionality. On the other hand, the means of cultural transmission, that is, imitative learning and teaching, also make use of human-specific social cognition. In contrast to the 'emulation learning' of (mother-reared) ${ }^{22}$ apes, which focuses on the changes in the environment caused by the action of the other, imitative learning is a much more social form of learning. Here, learning is accomplished by taking the role of the acting person. By doing this it becomes possible to distinguish between the means and the ends of the observed action. Thus, compared to emulation learning, imitation requires a much 'deeper' identification with the other. We not only learn from but through the other (Tomasello 1999: 6, 26ff.). In his recent writings Tomasello also emphasizes the motivational aspects of cultural learning. He claims that besides certain socio-cognitive skills, "humans' ultra-cooperative tendencies also play a role in the cultural ratchet" (Tomasello 2009b: xiv). This holds true for the altruistic act of teaching as well as for norms of conformity (Tomasello 2009b: xiv).

Without shared intentionality cumulative cultural traditions would not be possible. Yet, most importantly, shared intentionality does not only constitute the psychological basis of culture. Also, it is only with this cognitive and/or motivational basis in mind that it becomes possible to understand The Cultural Origins of Human Cognition. ${ }^{23}$ For Tomasello, the relation between cognition and culture is not a one-way street. Language may be the best example for this relation. According to Tomasello, language is not so much a product of biological but of cultural evolution. It does, of course, rely on biologically evolved human-specific skills. As demonstrated above, neither the use of symbols nor the cooperative structure of human communication would be possible without the capacity for shared intentionality. However, in Tomasello's social-pragmatic view, there is no such thing as innate universal grammar. On the contrary, the grammaticalization of language is a product of human cultural evolution - formed by sociogenesis and passed on by cultural learning (Tomasello 1999: 41-8). ${ }^{24}$ In turn, however, the culturally evolved capacity for language allows for the very efficient transmission of knowledge over generations. Furthermore, language defines how this knowledge is organized. The cultural structure of knowledge is passed on by means of language (Tomasello 1999: $165 \mathrm{ff}.)^{25}$ In other words, one of the results of cultural evolution - language fundamentally modifies the working of the very mechanism that allowed for its emergence. Consequently, it would be a mistake to say that cognition "is affected by" or "interacts with" cognition. Instead, "language is a form of cognition" (Tomasello 1999: 150).

Acquiring language thus leads children to conceptualize, categorize, and schematize events in much more complex ways than they would if they were not engaged in learning a conventionalized language, and these kinds of event 
representations and schematizations add great complexity and flexibility to human

cognition. (Tomasello 1999: 159) development of cognition also pervades the social character of cognition and action. That is because language not only provides a kind of 'cognitive grid' but also allows for the symbolic embodiment of perspectives. ${ }^{26}$ Children begin to understand perspectives as they engage in activities based on shared intentionality (Moll \& Tomasello 2007: 645). To understand perspective means to recognize that another person may have a differing view on the same thing. This recognition, in turn, presupposes that the individuals share their perceptions, attentions, and intentions. In these situations, one- to two-year-old children "begin to make active choices about how to construct things linguistically - this is a dog, an animal, a pet, a pest, or even 'it' - for purposes of interpersonal communication" (Tomasello \& Rakoczy 2003: 127). The toddlers thus actively choose between different simultaneously available symbolic perspectives. The appropriate use of symbols is acquired by role reversal, which is a special form of imitation learning. ${ }^{27}$ Thereby, the child learns that symbols are shared entities that can be used by you and me in both directions. Also, these children understand the normative dimension of symbols, that is, how they are used 'right' and 'wrong' as can be seen in wordplay. Symbols thus embody intersubjectively shared perspectives including a specific normative dimension (Tomasello \& Rakoczy 2003: 128). ${ }^{28}$

However, something important is missing in the symbolic and perspectival skills of these young children. For them what another person says does not represent something beyond this concrete symbolic act; there is no general belief behind the words or acts of the other. So, they understand intention, perspective and symbols but they have not yet acquired a full-fledged 'belief-desire'-psychology. Accordingly, for two-year-olds the norm related to a certain symbol or artifact applies only to that specifically and only with respect to the specific individual who formulated the norm.

For Tomasello, it is through continuous dialogical interaction in the third and fourth year of age that children begin to develop a much more mature understanding of the social world. In his view, two dialogical mechanisms are of particular importance for this transformation of social cognition. First, there is 'perspective-shifting discourse.' At some point after their second birthdays "children begin to command linguistic skills advanced enough to enable them to engage in more sophisticated discourse interactions with a real give-and-take of perspectives" (Tomasello \& Rakoczy 2003: 135). Now, the perspectives expressed are no longer the perspectives implicit in the linguistic symbols but the perspectives of the interlocutors themselves. In order to understand, children now have to take the role of the other. They shift their perspective and then relate it to their own perspective. With respect to the children's socio-cognitive development, disagreements and misunderstandings between peers and didactic meta-communications between the child and some authority seem to be the most important forms of perspective-shifting discourse. As Piaget observed, in peer discourse children need to clarify and reformulate their perspectives and often have to reconcile diverging perspectives. Hence, they are forced to explicate their view on a given situation and to distinguish between their perspective and that of the other. In contrast to peer discourse, in didactic interactions the child is likely to defer to the authority's view. Importantly, in this case there is still a dialogical interaction. However, it is internalized in the form of "reflective discourse" (Tomasello \& Rakoczy 2003: 136). Following Vygotsky, Tomasello claims that this leads to 
an enduring dialogical self-regulation of subsequent actions. Second, "propositional attitude constructions" (Tomasello \& Rakoczy 2003: 138f.) seem to be of some importance.

These constructions prototypically have some kind of psychological verb expressing a propositional attitude as the main verb (e.g., say, know, think, believe) and then a full proposition indicating what someone says, knows, thinks, or believes. (Tomasello \& Rakoczy 2003: 137)

The use of the propositional attitude constructions develops gradually and becomes more complex over time - especially between two-and-a-half and three-and-a-half years of age. Thus, it seems that children at this stage become able to differentiate between the truth value of the sentence "I think tomorrow will be Tuesday" (belief) and the sentence "Tomorrow will be Tuesday" (reality). Furthermore, this shows that children at that age begin to understand that syntactical constructions - like propositional attitude constructions - imply a certain perspective on things. ${ }^{29}$

Through the participation in a several year period of dialogical linguistic interaction children come to understand that others have beliefs that are more or less stable, that may differ from their own, and that may be wrong. That is to say, they are able to represent both the other and themselves as persons with beliefs and desires. Further, they understand collective practices and beliefs "which have the world-making power to create cultural-institutional realities" (Tomasello \& Rakoczy 2003: 139). Finally, they distinguish between beliefs and objective 'reality.' Thus language - one of the products of cumulative cultural evolution - shapes cognition not only by way of the transmission of knowledge and its structuring role for cognition but also because it deepens and generalizes the sociality of cognition and action..$^{30}$

Interestingly, Tomasello summarizes his argument with respect to Mead:

We may thus say that 2-year-olds participate in shared intentionality with specific other persons, whereas 5-year-olds participate in collective intentionality with individuals representing a broader set of cultural perspectives and norms. In the terms of Mead, the child is going from guiding its actions via an internalized 'significant other' to guiding its actions via an internalized 'generalized other.' (Tomasello \& Rakoczy 2003: 139)

Although Mead probably never used the concept of the 'significant other, ${ }^{31}$ such a reference 'points to' the close relationship between Tomasello and sociological pragmatism. Hence, a comparative analysis seems to be worthwhile.

\section{Tomasello's Cognitive Cultural Psychology and Sociological Pragmatism. Some Comparative and Critical Remarks}

Tomasello's work provides important theoretical insights as well as much-needed empirical backing for the understanding of the intrinsically social character of action. Therefore, I claim, it needs to be synthesized, to the furthest extent possible, with the arguably most radical and elaborated 'intrinsicalist' account of the sociality of action in the founding generation of the social sciences, namely, sociological pragmatism. To this end, the following sections of this chapter will briefly and critically compare Mead's, Cooley's, and Tomasello's contributions to each of the dimensions of the sociality of action. ${ }^{32}$ Thereby, we might not only be able to assess in how far pragmatist social theory can be confirmed and updated by recent findings in the human sciences. Also, it might 
become clear what needs to be added to a cultural psychology such as Tomasello's to successfully incorporate it into social theory.

Before I start with my theoretical reflections, however, I will present a short comparative description of the "disciplinary constellations" ${ }^{33}$ that gave rise to sociological pragmatism and Tomasello's cultural psychology in order to arrive at a deeper understanding of their striking similarities.

\section{IV. a) Disciplinary constellations}

By studying both the cognitive basis of culture and the sociocultural impact on cognition, Tomasello is one of the few cognitive scientists who gives center stage to social and cultural processes. On the one hand he adheres to the methods of experimental psychology and applies them to specific problems in developmental psychology, primatology, cognitive science, and linguistics in order to isolate those species-specific faculties that make possible human sociality and culture. On the other hand, his research designs are inspired by the extensive adoption of concepts and theories from philosophy, cultural theory, and sociology. While he repeatedly refers to arguments in the tradition of the later Wittgenstein, the decisive influence in the emergence of his cultural theory has probably been the cultural psychology of Lev Vygotsky, which he became acquainted with through his "second mentor" Jerome Bruner. ${ }^{34}$ Over the years, by combining these two levels of inquiry, Tomasello developed a cognitive cultural psychology based on elaborate experimental designs, which is characterized by profound interdisciplinarity and the effort to avoid dualistic and reductionist arguments.

Pragmatist social theory came to the fore in a disciplinary context quite different from the (again quite diverse) academic constellations that gave rise to the European 'classics.' Its protagonists did not try to constitute a new disciplinary field as, for example, Durkheim did. ${ }^{35}$ Rather, they tried to develop a new kind of social thought within the boundaries of their respective disciplines - be it philosophy and psychology (Mead) or economics and sociology (Cooley). This does not mean that they completely abstained from 'boundary work.' They not only strongly rejected the theological philosophy that dominated most American colleges, as well as all 'dualistic' philosophies, but also criticized many developments in economic thought. ${ }^{36}$ However, most importantly, since their boundary work did not aim at the institutionalization of a new discipline, they neither tried to marginalize other fields such as psychology, nor did they posit irreconcilable differences between academic areas such as the natural and the social sciences. For instance, while they rejected certain kinds of psychology (Herbartian association psychology, the 'structuralist' psychology of Titchener, etc.) they did dot reject psychology altogether but rather emphasized the importance or even contributed to the emerging fields of physiological, developmental and comparative psychology; ${ }^{37}$ while they criticized reductionist and biologistic positions they were also deeply influenced by new developments within physics and - as most American social scientists of their generation - by the Darwinian revolution ${ }^{38}$ However, by reading Darwin against an idealist or Hegelian background, authors such as Dewey, Cooley and Mead used evolutionary theory in a quite specific way.

Hence, we can conclude that both pragmatist social theory and the work of Tomasello emerged within 'disciplinary constellations' allowing for intensive scientific exchange between certain strands of philosophy, evolutionary theory, physiology, sociology and 
social, developmental and comparative psychology. Most importantly, however, neither of these authors fell prey to one-sided explanations of human action. Instead, each of them formulated a naturalist but non-reductionist account of human activity that stresses the evolutionary value of concepts such as consciousness, reflexivity, creativity, self or culture, often eschewed by psychologists and cognitive scientists as 'epiphenomena' or 'metaphysical entities.' Yet, these concepts are not rendered as metaphysical givens but rather as processes that emerge within the dynamics of human interaction with their social as well as non-social environments. Subsequently, however, these processes become of fundamental functional importance for these very interactions, thereby creating a qualitatively new form of sociality. ${ }^{39}$ While the impact of the "Hegelian bacillus" (Dewey) may explain the pragmatists' anti-reductionist take on Darwinism and psychology, ${ }^{40}$ Vygotsky's anti-behaviorist social and cultural psychology (which was strongly influenced by Marxism; cf. Cole \& Scribner (1978: 6ff.)) may do the same in the case of Tomasello. Finally, given the striking similarities between Mead's and Vygotsky's thought (Edwards 2007; Holland \& Lachicotte 2007), the affinity between pragmatism and Tomasello may not come as a surprise, after all.

\section{IV. b) Evolutionary Continuity, the "Holism of Difference," and Cultural Evolution (The Cultural Dimension)}

How can human beings be so alike yet so fundamentally different from their primate relatives or other 'higher' mammals? This is a question of crucial importance not only for Tomasello but also for sociological pragmatism. Each of the approaches wants to discover and explain 'the difference that makes the difference,' that is, the human-specific faculty that makes possible a social and cultural quantum leap. Yet, at the same time, each of them strives to understand this difference in terms of its evolutionary continuity.

In Mead, this twofold aim can clearly be seen in his comparative analyses of the gestures used in animal and human communication. By "embedding gestural language in the continuity of human with animal sociality" (Joas 1997 [1980]: 101) Mead tries to define the exact transition points where subhuman communication turns into human-specific communication. By this means, he hopes to discover the behavioral and sociopsychological underpinnings of human intersubjectivity and language:

Language, then, has to be studied from the point of view of the gestural type of conduct within which it existed without being as such a definite language. And we have to see how the communicative function could have arisen out of that prior sort of conduct. (Mead 1967 [1934]: 17)

The use of results from animal and comparative psychology is far from surprising, in this context. As Degler (1991: 32) points out, "[i]n none of the social sciences was this assumption of the relevance of animal behavior to the study of human beings more apparent than in the new science of psychology that was emerging in the last decades of the nineteenth century." Yet, in contrast to Tomasello, Mead does not refer to his own experimental research. Instead he repeatedly uses the example of an imaginary dogfight as a foil. ${ }^{41}$ In that context, Mead agrees and disagrees with Darwin at the same. While he highlights the necessity to understand human communication in terms of its evolutionary continuity he disagrees with Darwin's theory of emotional expression. Against Darwin and with Wundt, he stresses the social and expressive value of emotional expression and gestures in animals (e.g. Mead 1904: 382; 1909: 406f.). ${ }^{42}$ In Wundt's "vocal 
gesture" - which is not only perceived by the 'receiver' but also by the 'sender' - he discovers a 'transitional' concept necessary for the understanding of self-reflexivity as well as of the unique mechanism of human interaction (Mead's reasoning will become more clear in the following sections).

A comparable argument can be found in Cooley, who also emphasizes the importance of comparative studies:

[I]f we go far enough back we find that man and other animals have a common history, that both sprang remotely from a common ancestry in lower forms of life, and that we cannot have clear ideas of our own life except as we study it on the animal side and see how and in what respects we have risen above the conditions of our cousins the horses, dogs, and apes. (Cooley 2009 [1902/22]: 4)

Also for him, such a comparative perspective reveals the unique features of man, namely his flexibility and openness to cultural processes during ontogeny: "The difference is in teachability or plasticity. [...] This difference is fundamental to any understanding of the relation of man to the evolutionary process, or of the relation of human nature and human life to animal nature and animal life" (Cooley 2009: 19). In contrast to instinctdriven and hence inflexible animals who function like a "hand-organ," humans resemble a "piano": in contrast to the "hand-organ" "it is not made to play particular tunes; you can do nothing at all on it without training; but a trained player can draw from it an infinite variety of music" (Cooley 2009: 19). This conceptualization of 'humans' and 'animals' as 'ideal types, ${ }^{43}$ however, has its drawbacks because it does not allow for a convincing phylogenetic explanation of human-specific faculties in terms of their evolutionary continuity. This can also be seen from the fact that Cooley, in contrast to both Mead and Tomasello, does not posit the primacy of gestural communication in order to reconstruct the transition from non-human to human communication. ${ }^{44}$

For Tomasello, in turn, the question of evolutionary continuity is crucial since it is an "ineluctable conclusion [...] that individual human beings possess a biological inherited capacity for living culturally" (Tomasello 1999: 53). Culture cannot be completely explained by culture. Thus, in order to avoid a circular argument, a well-founded account of the evolutionary continuity between nonhuman and human primate cognition and behavior is indispensable. For Tomasello, to call this a reductionist position would, however, utterly miss the point (Tomasello 1999: 11). In contrast to other cognitive scientists he does not want "to skip from the first page of the story, genetics, to the last page of the story, current human cognition, without going through any of the intervening pages," namely, social interaction, cultural history and ontogeny (Tomasello 1999: 204). He stresses that the human-specific socio-cognitive capacity of shared intentionality must have been the result of a minor change in the socio-cognitive and/or motivational endowment. Indeed, given the short history of Homo sapiens (in evolutionary terms), anything more than a minor modification is highly improbable. ${ }^{45}$ This is why Tomasello repeatedly criticizes 'modular' or 'nativist' theories according to which the mind is made up by several "sub-programs" (Tooby \& Cosmides 2005: 17), each adapted for a highly specialized task and each with its own evolutionary history. ${ }^{46}$

Hence, Tomasello, as well as Mead and Cooley, uses results and theories from comparative psychology in order to identify the human-specific faculties that make possible human communication, society, and culture. While the coherence and details of their evolutionary accounts differ significantly, all of them agree that these faculties must be understood not only as products of gradual evolution but also as qualitatively new 
processes in the course of natural history. Consequently, both the pragmatist and Tomasello's accounts attempt to recognize what Matthias Jung calls "the doublestructure of the holism of difference and evolutionary continuity." ${ }^{47}$ That is to say, they do not only emphasize the enormous biological and cognitive similarities between humans and their nonhuman relatives ${ }^{48}$ but also stress the qualitatively new form of life that results from the minor evolutionary differences. For example, Tomasello acknowledges our primate nature but does not search - as his well-known colleague Frans de Waal does - for "Our Inner Ape" (de Waal 2006). Speaking of the "holism of difference" means to oppose "multi-story anthropologies" ("Stockwerkanthropologien") (Jung 2009: 198). Homo sapiens is not an ape with an additional layer of language, reason, or culture build on top, not a "genius-chimpanzee" or "chimpanzee-with-grammar" (Clark cited in Jung 2009: 57). In contrast, the concept of the "holism of difference" implies two major claims (Jung 2009: 55f.). On the one hand, it implies that the biologically evolved speciesspecific faculty impregnates the existence of this species as a whole, that is, even those 'aspects' that it 'shares' with other species. On the other hand, speaking of the holism of difference means that the human form of life cannot be understood 'bottom-up,' i.e., by cumulative understanding of its faculties. Rather, it must be understood as an integrative whole. Thus in Mead's theory of interaction, intersubjectivity and self-reflexivity; in Cooley's account of sociability, sympathy and the looking-glass self; just as in Tomasello's conceptualization of shared intentionality and ultra-cooperativeness, certain crucial specific capacities of humans also impregnate their perception, memory, attention, categorization, bodily movements, etc. - all aspects we share with other primates.

In addition, according to Tomasello, the recognition of the evolutionary continuity of human nature calls for an alternative mechanism of cognitive transformation. In contrast to the above mentioned modular views, for him, human cognition and action can only be explained by granting a decisive role to cumulative cultural evolution which - compared to biological processes - works "on a completely different time scale" (Tomasello 1999: 207). Thus, while Tomasello wants to identify the socio-cognitive foundations of culture, he does not try to reduce culture to some overriding biological processes. Instead, he strives for an understanding of the psychological mechanisms that allowed for the cultural process to branch off of biological evolution, thereby constituting a relatively autonomous process which must be understood in its own terms. In other words, according to Tomasello, human society and culture can only be explained by means of dual inheritance theory, that is, by considering not only natural as well as cultural evolution but also their complex interdependencies. ${ }^{49}$

Again, a similar, if less detailed, argument can be found in the work of the pragmatists. In Cooley's Human Nature and the Social Order, for example, we can find a powerful metaphor for the interplay of "heredity" and "social transmission." Here, he draws on the image of "a stream and a road running along the bank" (Cooley 2009: 4) in order to characterize the relationship between the "two channels of life," i.e., between cultural and natural evolution. While the road is more recent than the river, in the course of human evolution it becomes "more and more distinct and travelled, and finally develops into an elaborate highway, supporting many kinds of vehicles and a traffic fully equal to that of the stream itself" (Cooley 2009: 5). In the life of the individual, these two processes become "a total organic process not separable into parts" (Cooley 2009: 15). Hence, according to Cooley, natural and cultural evolution should not be seen as antagonistic but as complementary. 
, just like Tomasello, Cooley does not want to skip from the first to the last page in order to explain human activity and cognition, either. These phenomena can neither be understood as genetically fixed and hence 'hard-wired' nor as passively imprinted by culture. For Cooley, human agency is the result of active interpersonal interchange within the primary group that serves as a kind of cultural transmitter. Most importantly, however, human agency is not only triggered by the socio-cultural environment but takes a certain cultural form depending on its context. This is to say, plasticity is linked to the sociality and culturality as well as to historicity of human nature.

Human history, in distinction from animal history [...] is a process possible only to a species endowed with teachable instinctive dispositions, organized, partly by reason, into a plastic and growing social whole. This whole, responsive to the outer world in a thousand ways, and containing also diverse and potent energies within itself, is ever putting forth new forms of life, which we describe as progress or decadence according as we think them better or worse than the old. These changes do not require any alteration in our hereditary powers. (Cooley 2009: 31)

Also, for Tomasello, humans are the "paradigmatic cultural species" since their culture is not only "quantitatively" but also "qualitatively unique" (Tomasello 2009b: ix, x). Because of their ontogenetic receptivity humans develop genuine cultural cognition. With respect to social cognition this leads to a new form of deepened and generalized shared intentionality. Consequently, the 'qualitative' disparity ${ }^{50}$ between the activities and cognitions of humans and animals builds up not only on their socio-cognitive and/or motivational differences but also on the effects of the cultural dimension of sociality, which itself became possible in the first place on the basis of this psychological infrastructure. The use of symbols and language illustrates these cognitive changes through culture. As Vygotsky already noted:

Although practical intelligence and sign use can operate independently of each other in young children, the dialectical unity of these systems in the human adult is the very essence of complex human behavior. Our analysis accords symbolic activity a specific organizing function that penetrates the process of tool use and produces fundamentally new forms of behaviour. (Vygotsky 1978 [1930-35]: 24; see also $45 \mathrm{ff}$.)

In other words: the effects of the cultural ratchet change the ratchet's mode of operation. This is why Tomasello approves of Mead's claim that "there is nothing odd about the product of a given process contributing to, or even becoming an essential factor in, the further development of that process" (Tomasello 1999: 13; cf. Mead 1967 [1934]: 226).

So far, the comparative discussion of Tomasello and sociological pragmatism focused on the relation of natural and cultural evolution as well as on the impact of the sociocultural environment on cognition. Now, however, the question arises why humans are able to partake in the sociocultural process (c) and why they are motivated to do so (d). In other words, Tomasello's account of the cognitive and motivational dimension of the sociality of action needs to be compared to corresponding arguments in the works of the pragmatists.

\section{IV. c) Tomasello's Elaboration of the Cognitive Roots of Human Sociality (The Cognitive Dimension)}

53 Arguably, the most important and radical contribution of sociological pragmatism to social theory is the claim that the problems of human agency and of human sociality are 
not two distinct problems but two aspects of the same problem. This is why we need to look into social interaction and social cognition in order to understand the self-reflexive and conscious activity of the individual. Yet, in order to understand the co-evolution of these two aspects we cannot begin with human specific communication. Instead, as can be seen in the work of Mead and Tomasello, an anthropological theory of action must begin with the most basic and hence 'sub-human' forms of interaction to identify the 'transition points' where non-human interaction turns into human-specific interaction. This explains why Mead and Tomasello assert the methodological primacy of gestural communication over speech (cf. e.g. Mead 1904: 79ff.; Mead 1910a: 397ff.; Tomasello 2008: $53 \mathrm{ff}.)^{51}$

Most importantly, primate gestural communication is conceptualized not as an imitative but as a cooperative interaction. Each of the three authors discussed in this paper rejects those kinds of imitation-theory that regard imitation as the basic intersubjective process which makes interaction, enculturation, learning, understanding etc. possible. ${ }^{52}$ Mead, Cooley, and Tomasello argue convincingly that imitation cannot be seen as 'transitional' concept since it already presupposes self-reflexivity and human-specific interaction:

When another self is present in consciousness doing something, then such a self may be imitated by the self that is conscious of him in his conduct, but by what possible mechanism, short of a miracle, the conduct of one form should act as a stimulus to another to do, not what the situation calls for, but something like that which the first form is doing, is beyond ordinary comprehension. Imitation becomes comprehensible when there is a consciousness of other selves, and not before. However, an organization of social instincts gives rise to many situations which have the outward appearance of imitation, but these situations - those in which, under the influence of social stimulation, one form does what others are doing - are no more responsible for the appearance in consciousness of other selves that answer to our own than are the situations which call out different and even opposed reactions. Social consciousness is the presupposition of imitation. (Mead 1909: 405f.)

Indeed, as Mead notes at the end of the first sentence of the quote, it would not even be functional if imitation were the basic mechanism of human interaction. Instead, in most situations, efficient interaction only occurs if the members of a group carry out different actions that complement each other. Yet, because human individuals are deprived of instinctive behavioral patterns an evolutionary new mode of coordination is needed which makes possible institutionalized behavioral patterns. Despite their contingent character, these patterns would allow for a relative predictability of the behavior of others.

Such a new form of coordination, however, presents a serious challenge to social cognition. As long as we deal with non-social objects the coordination of action is relatively simple. But as soon as other social objects, that is, other individuals, become part of the situation everything changes..$^{53}$

A man's reaction toward weather conditions has no influence upon the weather itself. It is of importance for the success of his conduct that he should be conscious not of his own attitudes, of his own habits of response, but of the signs of rain or fair weather. Successful social conduct brings one into a field within which a consciousness of one's own attitudes helps toward the control of the conduct of others. (Mead 1910a: 403)

57 Hence, in situations where humans interact with each other self-reflexivity becomes functional and necessary for the first time in natural history. 
Yet, why does self-reflexivity present a challenge to social cognition? The answer to this question is 'role-taking.' Cooley, Mead, and Tomasello agree that humans are able to act in a self-reflexive way only because they can take the role of the other, that is, only because they can look at themselves from the 'outside.' Only if the individual experiences itself as a social object self-reflexivity or identity emerges. This is why we need to analyze social cognition in order to explain self-reflexivity.

While the three authors agree on this account of the relationship between role-taking and self-reflexivity, their works vary greatly in their degree of detail and their accuracy. In Cooley, we find a detailed discussion of the interplay of sympathy, role-taking, imagination, and identity. However, he does not connect this argumentation to the problem of gestural communication, interaction, and coordination in any systematic way. In contrast, the relation between gestural communication and social coordination on the one hand and role-taking and self-reflexivity on the other is central to Mead. Something similar holds true for Tomasello, whose work, however, discusses the different cognitive processes involved in social interaction in greater detail and presents experimental proof for many of its claims. Moreover, in contrast to Mead, Tomasello provides a detailed chronological developmental psychology not only the "developmental logic" of cognitive maturation (Joas 1997 [1980]: 119f.).

Most importantly, however, I think that Tomasello's theory might be able to fill a crucial gap in Mead's account. As already mentioned, Mead draws on Wundt's concept of the "vocal gesture" in order to explain how an individual becomes self-reflexive. In contrast to facial and bodily expressions, so the argument goes, the vocal gesture can not only perceived by other individuals but also by the individual who performs the gesture. Because the 'sender' is affected by his own vocal gesture he can then associate this selfaffection with the 'attitude' of the other which has been observed before:

1 In so far then as the individual takes the attitude of another toward himself, and in some sense arouses in himself the tendency to the action, which his conduct calls out in the other individual, he will have indicated to himself the meaning of the gesture (Mead 1922: 161).

Yet, if we look at singing birds or barking dogs; or if we think of manual gestures - which can also be observed by the 'sender' (as Mead himself notes (cf. 1922: 160)) -, the question arises: what is special about human vocal gestures? In some of Mead's texts it seems as if his argument completely relies on this concept (cf. Mead 1913: 376f.). At least in one text, however, Mead himself acknowledges that it is not sufficient to refer to the vocal gesture alone.

Of course the mere capacity to talk to oneself is not the whole of self-consciousness, otherwise the talking birds would have souls or at least selves. What is lacking to the parrot are the social objects which can exist for the human baby. (Mead 1912: 405)

While he acknowledges the problem, Mead does not, in my opinion, adequately address the further requirements of self-reflexivity. With reference to Mind, Self \& Society Hans Joas and Harald Wenzel argue that Mead posits the "reduction of instincts" and the "constitutional uncertainty of reaction" in humans which, in turn, result from physiological changes of the central nervous system and the cerebral cortex, as further preconditions for self-reflexivity (Joas 1997 [1980]: 115; cf. Wenzel 1990: 71f.). Yet, even if this is correct, the question still is: what are the cognitive preconditions that allow for intersubjectivity and agency in the face of human 'instinct reduction' and 'uncertainty of 
reaction'? Mead, I think, does not answer the question. Hence, it might be worthwhile to attempt to fill this gap with Tomasello's detailed account of human social cognition. This, however, cannot be discussed here in detail.

Overall, not only with respect to the cognitive underpinnings of intersubjectivity Tomasello's argument shows marked similarities to that of Mead. As becomes clear in his writings on cooperation, the reference to Mead is also important when it comes to the question of motivation: "Initially children base such 'we-ness' on identification with significant-other individuals such as parents and family and schoolmates (G. H. Mead's significant other), and only later generalize them into truly impersonal cultural norms based on identification with some type of cultural group (G. H. Mead's generalized other)" (Tomasello 2009b: 41f.). Thus, we should look into the similarities and difference with regard to the motivational dimension of the sociality of action. Why, so the basic question, do we strive for social contact and cooperation, in the first place?

\section{IV. d) An Overly Harmonious View of Human Action? (The Motivational Dimension)}

65 To refer to 'instincts' in contemporary social theory to identify the motivation for a certain human activity is not really en vogue, to say the least. Around 1900, however, a great number of instinct theories were discussed in the social sciences, especially in the United States. Some of them listed dozens or even hundreds of different instincts. Apart from the sporadic early criticisms of Carl Kelsey, Franz Boas or Luther L. Bernard, the "assault on instinct theory" only started in the early 1920s (cf. Collier et al. 1991: 32-4; Degler 1991: 157ff.). Like many other social scientists the pragmatist authors for a long time maintained an ambivalent attitude towards instinct theory. It was not until 1921 that Ellsworth Faris, a disciple of Mead, rejected instinct-theory completely by stating that "genetic explanation is a sort of mythological effort and has resulted in rather ludicrous stories which pass as explanations" (Faris 1921: 84).

Today, the concept of 'instinct' is associated with biologistic and reductionist theories that completely deprive the individual organism of self-reflexivity, empathy or prosocial motivations. Mead, however, aimed at a non-reductionist anthropological theory of intersubjectivity and self-reflexivity. Why, then, was he attracted by instinct-theory? In his review of McDougall's Introduction to Social Psychology (1960 [1908]) - one of the first textbooks of social psychology and a seminal contribution to instinct-theory - Mead writes:

The most important feature of this analysis of Mr. McDougall, in the mind of the reviewer, is that it makes the ultimate unit an act rather than a state of consciousness. All consciously formed habits are regarded as in a sense derivatives of these instincts and servants of them. All the motive power of conduct is found in them. All the complexities of thought and action are explained through the complications of the instincts and their stimuli and motor responses. (Mead 1908: 386)

This quote suggests that Mead embraces 'instinct-theory' because he regards it as a possible way out of the contradictions of the traditional philosophy of consciousness (cf. Joas 1997 [1980]: 93). Because instinct-theory takes its start from the analysis of the instinctive behavior of an individual organism in its environment, higher psychological processes need to be explained not only in terms of their functional value for the organism but also on the basis of these basic activities. Hence, in Mead's view, instinct 
theory does not assume what needs to be proved, namely, self-reflexivity and consciousness. ${ }^{54}$ Moreover, the integration of the concept of 'social instincts' into instinct theory - that can already be found in Darwin (1981 [1872]: 79ff.) and that takes central stage in McDougall - not only suggests the above mentioned distinction between social and non-social objects but also implies the impulse to interact with others in various ways..$^{55}$ Here, we can not only locate the starting point of a possible theory of motivation in Mead but also the need to combine it with his account of intersubjectivity. Yet, in spite of these important insights, there is no systematic discussion of the motivational dimension of the sociality of action in the work of Mead. Two theoretical problems need to be considered in order to account for this shortcoming. First, Mead drew on instincttheory only in his earlier studies. Like many other social scientists "Mead, too, later dissociated himself from the psychology of instincts and became an adherent of the weaker version of this theory which held that the impulses are the remnants of instincts in human beings" (Joas 1997 [1980]: 93f.). For example, in his 1929 study "National mindedness and international mindedness," Mead only presupposes two natural and rather diffuse impulses, namely, solidarity and aggression (Joas 1997: 119). These "natural impulses," then, become part of his concept of the "I" as the spontaneous, creative, and impulsive part of the self (Joas 1997: 117). Second, Mead not only changed the conceptual framing of his motivational 'theory' but also failed to connect it to his theory of identity (Joas 1997: 117).

In contrast to Mead, Cooley was skeptical of instinct-theory from the start. Humans, according to Cooley, are motivated not by fixed instincts but by "instinctive emotions" which "are rapidly developed, transformed, and interwoven by social experience, giving rise to a multitude of complex passions and sentiments [...]. Indeed, as these change very considerably with changes in the social life that moulds them, it is impossible that they should be defined and finally described" (Cooley 2009 [1902/22]: 27). While this seems to be a possible starting point for a cultural sociology of motivation and emotion (cf. Nungesser 2012) it does not explain in any conclusive way why human beings have such a strong impulse to partake in social interaction.

In Cooley, such an explanation can most likely be found in his account of human “sociability" (Cooley 2009 [1902/22]: 81-135). For Cooley, sociability initially manifests itself in children's "susceptibility to touches, tones of voice, gesture, and facial expression" (Cooley 2009: 5, see also 103). At the beginning they strive for contact with others mainly in search of "stimulating suggestions" (Cooley 2009: 84), later - when they are around one year of age - their "social feeling" enables them to distinguish social objects from other kinds of stimulation. Towards these objects "the child has by heredity a generous capacity" (Cooley 2009: 86). Children want to share their experiences with others. They allow them to express themselves which is of crucial importance for their further development (Cooley 2009: 85). Yet, sociability involves not only an expressive but also a receptive dimension since it also implies the willingness to imagine the thoughts and sentiments of others. This is why the emergence of an "imaginary playmate" is a decisive step in the development of sociability (Cooley 2009: 88ff.). For Cooley, the conversations with this playmate have to be regarded as "the naïve expression of a socialization of the mind that is to be permanent and to underlie all later thinking" (Cooley 2009: 89). In other words, in these interactions the intersubjective, dialogical and imaginative character of cognition and action becomes apparent (Cooley 2009: 89ff., 360ff.). From then on the "mind lives in perpetual conversation" (Cooley 2009: 
90) and through this imaginative effort, that is, through the constant imagination of other people's thoughts and sentiments "our personality is built up" (Cooley 2009: 97). ${ }^{56}$

Yet, just as Mead, if for quite different reasons, Cooley does not arrive at a full-fledged theory of motivation. While he pays more attention to impulses and emotions than Mead does, he fails to connect his theory of sociability (motivational dimension) with his theory of sympathy or understanding (cognitive dimension). ${ }^{57}$

In spite of its shortcomings, Cooley's concept of "sociability" shows marked similarities to Tomasello's account of the motivational dimension of sociality. Just like Tomasello, Cooley emphasizes the spontaneous character of the children's expressivity and generosity. Also, for Tomasello, to help and to express themselves is a "naturally emerging behavior" in children (Tomasello 2009b: 7). In his view humans are "born (and bread) to help" (Tomasello 2009b: 1). So, if he had to choose between Hobbes and Rousseau, Tomasello would side with the latter (Tomasello 2009b: 3). Hence, the question arises: why isn't there love and peace everywhere in the world? Isn't this "Rousseau first, Hobbes second" hopelessly naïve? Don't we have to "Bring the Beasts Back in," as van den Berghe put it (1974)? Of course, Tomasello is aware of this possible misunderstanding.

For all parents who think their child must have skipped the naturally cooperative stage, let me quickly note that we are talking here about a behavior measured in relation to other primates. All viable organisms must have a selfish streak; they must be concerned about their own survival and well-being or they will not be leaving many offspring. Human cooperativeness and helpfulness are, as it were, laid on top of this self-interested foundation. (Tomasello 2009b: 5)

I consider this intuitively plausible claim to be profoundly problematic. Homo sapiens is conceptualized here as a kind of 'chimpanzee-plus-helpfulness.' That is to say, Tomasello slides into a kind of 'multi-story anthropology' that splits the human individual into a savage and egocentric ape and an altruistic and empathic human. The result would be a two-part theory of action: one part dealing with the explanation of self-interested action on the basis of nonhuman primate behavior; another part dealing with disinterested action on the basis of human-specific social cognition and motivations. However, in order to avoid such an anthropological conception that contradicts the aforementioned holism of difference all kinds of actions must be understood against the background of the qualitatively distinct human form of life.

This does not lead to an overly harmonious view of human action. Humans can, of course, be "both competitive and cooperative" (Moll \& Tomasello 2007: 640). However, the crucial insight is that human self-interested actions are qualitatively different from that of apes. Just as cooperative actions they draw heavily on species-specific skills. In his phylogenetic account of the Origins of Human Communication, Tomasello expresses this view quite clearly:

Our proposal is that human cooperative communication was adaptive initially because it arose in the context of mutualistic collaborative activities in which individuals helping others were simultaneously helping themselves. This is not quite as obvious as it first sounds, as cooperative communication today may be used for all kinds of selfish, deceptive, competitive, and otherwise individualistic ends. (Tomasello 2008: 170)

74 Hence, compared with nonhuman primates, completely new modes of egoistic actions become possible. For example, lying and deception is only possible on the complex basis of recursive mindreading and an understanding of common ground. What is more, even the most vicious acts like sadism or torture draw heavily on these social cognitive skills. 
Consequently, based on an account of the intrinsic sociality of cognition and action a better understanding of cooperative as well as competitive and even amoral or vicious action becomes possible. Humans can, of course, act egoistically, sadistically, or antisocially but they rarely act egocentrically in the true sense of the word.

\section{Final Remarks}

The comparison and potential synthesis of sociological pragmatism and recent developments in the cognitive sciences would, of course, require a more detailed discussion. Yet, it should already have become clear that an intense dialogue between authors such as Tomasello and the pragmatists holds a lot of promise. By entering into this dialogue, one remains faithful to the pragmatist project and its transdisciplinary aspiration. This dialogue might also be the first step to a pragmatist perspective on present debates on social cognition, we-intentions, or the evolution of human sociality.

Because it contributes to an elaborate account of its anthropological double-structure Tomasello's work may be of great importance for an understanding of human action as both evolutionary continuous and qualitatively different. Yet, as has been shown in section IV (d), some remnants of "multi-story-anthropologies" might be found in his work. Then, it sounds like the species-unique skills are just "laid on top of" (Tomasello 2009b: 5) or "added" to (Tomasello 2009b: 39) nonhuman primate cognition.

Most importantly, however, it must be seen that Tomasello can be of crucial importance for an account of the fundamental anthropological foundations of human agency. He cannot, however, answer sociological questions regarding status, emotions, power or social norms. These concepts are necessarily linked to the problems discussed in this paper. How exact the interplay between these processes works, however, needs to be discussed in future sociological research.

\section{BIBLIOGRAPHY}

Aввотт A., (1999), Department \& Discipline. Chicago Sociology at One Hundred, Chicago, University of Chicago Press.

BARON-COHEN S., (1995), Mindblindness. An Essay on Autism and Theory of Mind, Cambridge, MIT Press. BERnSteIn R., (2010), The Pragmatic Turn, Cambridge, Polity Press.

BESNARD P., (1981), "Die Bildung des Mitarbeiterstabs der Année sociologique," in Lepenies Wolf (ed.), Geschichte der Soziologie. Studien zur kognitiven, sozialen und historischen Identität einer Disziplin, 4 Vol., Frankfurt am Main, Suhrkamp, 263-302.

BRUNER J. S., (1995), “Vygotsky: A Historical and Conceptual Perspective," in Wertsch James V. (ed.), Culture, Communication, and Cognition: Vygotskian Perspectives, Cambridge, Cambridge University Press, 21-34. 
BUSS D. M., (1995), “Evolutionary Psychology. A New Paradigm for Psychological Science," Psychological Inquiry, 6 (1), 1-30.

Call J. \& M. Tomasello, (1999), “A Nonverbal False Belief Task: The Performance of Children and Great Apes," Child Development, 70 (2), 381-95.

CALl J. \& M. TOMASELlo, (2008), "Does the Chimpanzee Have a Theory of Mind? 30 Years Later," Trends in Cognitive Sciences, 12 (5), 187-92.

CLARK H. H., (1996), Using Language, Cambridge, Cambridge University Press.

CLARK A., (1998), "Magic Words. How Language Augments Human Computation," in Carruthers P.\& Boucher J. (eds.), Language and Thought. Interdisciplinary Themes, Cambridge, Cambridge Univiversity Press, 162-83.

COLE M. \& S. SCRIBNER, (1978), "Introduction," in Vygotsky Lev S., Mind in Society. The Development of Higher Psychological Processes, ed. by M. Cole, V. John-Steiner \& S. Scribner et al., Cambridge, Harvard University Press, 1-16.

COLLIER G., MINTON H. L. \& G. REYNOLDS, (1991), Currents of Thought in American Social Psychology, New York, Oxford University Press.

COOLEY C. H., (2009 [1902/22]), Human Nature and the Social Order, New Brunswick, Transaction Publ.

DARWIN C., (1981 [1872]), The Descent of Man, and Selection in Relation to Sex, Princeton, Princeton University Press.

DEWEY J. (1896), "The Reflex Arc Concept in Psychology," The Early Works of J. Dewey, 1982-1898, vol. 5 (EW 5), ed. by J. A. Boydston, Southern Illinois University Press, Carbondale and Edwardsville 1972.

DEWEY J. (1917), “The Need for Social Psychology,” The Middle Works of J. Dewey, 1899-1924, vol. 10 (MW 10), ed. by J. A. Boydston, Southern Illinois University Press, Carbondale and Edwardsville 1980.

DEWEY J., (1922), Human Nature and Conduct, The Middle Works of J. Dewey, 1899-1924, vol. 14 (MW 14), ed. by J. A. Boydston, Southern Illinois University Press, Carbondale and Edwardsville 1983.

DURKHEIM É., (1979 [1897]), Suicide. A Study in Sociology, ed. by George Simpson, New York, The Free Press.

DURKHEIM É., (2004 [1893]), Über soziale Arbeitsteilung. Studie über die Organisation höherer Gesellschaften, Frankfurt am Main, Suhrkamp.

FARR R. M., (1996), The Roots of Modern Social Psychology. 1872-1954, Oxford, Blackwell.

EDWARDS A., (2007), “An Interesting Resemblance: Vygotsky, Mead, and American Pragmatism,” in Daniels H., Cole M. \& Wertsch J. V. (eds.), The Cambridge Companion to Vygotsky, Cambridge, Cambridge University Press, 77-100.

GARDNER R. A. \& B. T. GARDNER, (1989), “A Cross Fostering Laboratory,” in Gardner R. A., Gardner B. T. \& van Cantfort T. E. (eds.), Teaching Sign Language to Chimpanzees, Albany, N.Y., State University of New York Press, 1-28.

GREENWOOD J. D., (2004), The Disappearance of the Social in American Social Psychology, New York, NY, Cambridge University Press. 
HOLLAND D. \& LACHICOTTE W. Jr. (2007), "Vygotsky, Mead, and the New Sociocultural Studies of Identity," in Daniels H., Cole M. \& Wertsch J. V. (eds.), The Cambridge Companion to Vygotsky, Cambridge, Cambridge University Press, 101-35.

JACOBS G., (2009), "Influence and Canonical Supremacy. An Analysis of How George Herbert Mead Demoted Charles Horton Cooley in the Sociological Canon," Journal of the History of the Behavioral Sciences, 45 (2), 117-44.

JOAS H., (1993), Pragmatism and Social Theory, Chicago, The University of Chicago Press.

JOAS H., (1996), The Creativity of Action, Chicago, The University of Chicago Press.

JOAS H., (1997 [1980]), G. H. Mead. A Contemporary Re-Examination of his Thought, Cambridge, MIT Press.

JUNG M., (2009), Der bewusste Ausdruck. Anthropologie der Artikulation, Berlin, de Gruyter.

KAMINSKi J., CALL J. \& M. TOMASELlo, (2008), “Chimpanzees Know What Others Know, But Not What They Believe," Cognition 109, 224-34.

KARADY V., (1981), "Strategien und Vorgehensweisen der Durkheim-Schule im Bemühen um die Anerkennung der Soziologie," in Lepenies Wolf (ed.), Geschichte der Soziologie. Studien zur kognitiven, sozialen und historischen Identität einer Disziplin, 4 Vol., Frankfurt am Main, Suhrkamp, 206-262.

LEPENIES W., (1981), “Einleitung. Studien zur kognitiven, sozialen und historischen Identität der Soziologie," in Lepenies Wolf (ed.), Geschichte der Soziologie. Studien zur kognitiven, sozialen und historischen Identität einer Disziplin, 4 Vol., Frankfurt am Main, Suhrkamp, i-xxxv.

MCDougall W., (1960 [1908]), An Introduction to Social Psychology, London, Methuen\&Co.

MEAD G. H., (1903), “The Definition of the Psychical," Decennial Publications of the University of Chicago, III, 77-112. [brocku.ca/MeadProject/Mead/pubs/Mead_1903.html].

MEAD G. H., (1904), “The Relations of Psychology and Philology," Psychological Bulletin 1, 375-91. [ brocku.ca/MeadProject/Mead/pubs/Mead_1904c.html]

MEAD G. H., (1908), “McDougall's Social Psychology," Psychological Bulletin 5, 385-91. [brocku.ca/ MeadProject/Mead/pubs/Mead_1908f.html].

MEAD G. H., (1909), “Social Psychology as Counterpart to Physiological Psychology," Psychological Bulletin 6, 401-8. [brocku.ca/MeadProject/Mead/pubs/Mead_1909a.html].

MEAD G. H., (1910a), “Social Consciousness and the Consciousness of Meaning," Psychological Bulletin 7, 397-405. [brocku.ca/MeadProject/Mead/pubs/Mead_1909a.html].

MEAD G. H., (1910b), “What Social Objects Must Psychology Presuppose?," Journal of Philosophy, Psychology and Scientific Methods 7, 174-80. [brocku.ca/MeadProject/Mead/pubs/Mead_1910d.html ].

MEAD G. H., (1912), “The Mechanism of Social Consciousness," Journal of Philosophy, Psychology and Scientific Methods 9, 401-6. [brocku.ca/MeadProject/Mead/pubs/Mead_1912a.html].

MEAD G. H., (1913), “The Social Self," Journal of Philosophy, Psychology and Scientific Methods 10, 374-80. [brocku.ca/MeadProject/Mead/pubs/Mead_1913.html].

MEAD G. H., (1922), “A Behavioristic Account of the Significant Symbol," Journal of Philosophy 19, 157-63. [brocku.ca/MeadProject/Mead/pubs/Mead_1922.html]. 
MEAD G. H., (1967 [1934]), Mind, Self \& Society. From the Standpoint of a Social Behaviorist, ed. by Charles Morris, Chicago-London, The University of Chicago Press.

MEAD G. H., (2009 [1930]), “Cooley's Contribution to American Social Thought," in Cooley C. H., Human Nature and the Social Order, New Brunswick, Transaction Publ., xxi-xxxviii.

MOLL H. \& M. TOMASELlo, (2007), “Cooperation and Human Cognition: The Vygotskian Intelligence Hypothesis," Philosophical Transactions of the Royal Society B, 362 (1480), 639-48.

NUNGESSER F., (2012), “Charles Horton Cooley: 'Human Nature and the Social Order', "in Senge K. \& Schützeichel R. (eds.), Hauptwerke der Emotionssoziologie, Wiesbaden, VS (forthcoming).

PEIRCE C. S., (1998 [1903]), "Nomenclature and Divisions of Triadic Relations, as Far as They are Determined," in Peirce C. S., The Essential Peirce. Selected Philosophical Writings, Vol. 2., ed. by Peirce Edition Project, Bloomington, Indiana University Press, 289-99.

PINKER S., (2000), The Language Instinct. How the Mind Creates Language, New York, NY, HarperPerennial.

SCHEFF T. J., (2003), “Looking-Glass Self: Goffman as Symbolic Interactionist," Symbolic Interaction, $28(2), 147-66$.

SCHUBERT H.-J., (1995), Demokratische Identität. Der soziologische Pragmatismus von Charles Horton Cooley, Frankfurt am Main, Suhrkamp.

TAYLOR C., (1997 [1989]), “Cross-Purposes: The Liberal-Communitarian Debate," in Taylor C., Philosophical Arguments, Cambridge, Harvard University Press, 181-203.

TERRACE H. S., Petitto L. A., SANDERs R. J. \& T. G. BeVer, (1979), “Can an Ape Create a Sentence?,” Science, 206 (4421), 891-902.

THAYER H. S., (1981), Meaning and Action. A Critical History of Pragmatism, Indianapolis, New York, Bobbs-Merrill.

TOMASELlo M., (1995), “Language is Not an Instinct," Cognitive Development 10, 131-56.

TOMASELlo M., (1999), The Cultural Origins of Human Cognition, Cambridge, Harvard UP.

TOMASELlo M., (2005), Constructing a Language. A Usage-Based Theory of Language Acquisition, Cambridge, Harvard University Press.

tomasello M., (2006), “Why Dont' Apes Point?,” in Enfield N. J. \& Levinson S. C. (eds.), Roots of Human Sociality. Culture, Cognition and Interaction, Oxford, Berg, 506-24.

TOMASELlo M., (2008), Origins of Human Communication, Cambridge Mass., MIT Press.

TOMASELLO M., (2009 [1999]), Die kulturelle Entwicklung des menschlichen Denkens. Zur Evolution der Kognition, Frankfurt am Main, Suhrkamp.

TOMASEllo M., (2009a), “Rede, gehalten anlässlich der Verleihung des Hegel-Preises 2009 am 16. Dezember 2009 in Stuttgart” (English Version). [stuttgart.de/img/mdb/item/383875/51641.pdf]. TOMASELlo M., (2009b), Why We Cooperate. Based on the 2008 Tanner Lectures on Human Values at Stanford, Cambridge-London, MIT Press.

TOMASello M. \& J. CAll, (1997), Primate Cognition, New York, Oxford University Press.

Tomasello M., CALL J. \& B. HARE, (2003), "Chimpanzees Understand Psychological States - The Question Is Which Ones and To What Extend," Trends in Cognitive Sciences, 7 (4), 153-6. 
TOMASEllo M. \& H. RAKoczY, (2003), “What Makes Human Cognition Unique? From Individual to Shared to Collective Intentionality," Mind \& Language, 18 (2), 121-47.

tomasello M., SAVAge-Rumbaugh S. \& A. C. KRUger, (1993), "Imitative Learning of Actions on Objects by Children, Chimpanzees, and Enculturated Chimpanzees," Child Development 64, 1688-1705.

TOMASELlo M. \& G. scobel, (2008), “Interview: Michael Tomasello,” 3 Sat. [3sat.de/mediathek/ mediathek/10125].

тоову J. \& L. cosmides, (2005), “Conceptual Foundations of Evolutionary Psychology,” in Buss D. M. (ed.), The Handbook of Evolutionary Psychology, Hoboken, John Wiley \& Sons, 5-67.

VAN DEN BERGHE P., (1974), "Bringing Beasts Back In. Toward a Biosocial Theory of Aggression," American Sociological Review, 39 (6), 777-88.

VYGOTSKY L. S., (1978 [1930-35]), Mind in Society. The Development of Higher Psychological Processes, ed. by M. Cole, V. John-Steiner, S. Scribner, et al., Cambridge, Harvard University Press.

WAAL F. B. M. de, (2006), Our Inner Ape. A Leading Primatologist Explains Why We Are Who We Are, New York, Riverhead Books.

WEBER M., (2007 [1922]), Economy and Society. An Outline of Interpretive Sociology, Berkeley, University of California Press.

WENZEL H., (1990), George Herbert Mead zur Einführung, Hamburg, Junius.

WIMMER H. \& J. PERNER, (1983), "Beliefs about Beliefs. Representation and Constraining Function of Wrong Beliefs in Young Children's Understanding of Deception," Cognition 13, 103-28.

YULE G., (2010), The Study of Language, Cambridge, Cambridge University Press.

\section{NOTES}

1. For a comprehensive critique of the Disappearance of the Social in American Social Psychology see Greenwood 2004. Critical accounts can also be found in Collier et al. 1991, and Farr 1996. To speak of 'psychological social psychology' is not tautological. For the difference between 'sociological' and 'psychological' social psychology and its emergence see Collier et al. (1991: 8-10).

2. Another problem in Weber's methodological writings is that he defines social action as meaningful action (as opposed to mere behavior). Since he defines sociology as "the science concerning itself with the interpretative understanding of social action" (Weber 2007 [1922]: 4) a broad range of social phenomena like, for example, habitus and habits would not be part of sociological research. Yet, Weber himself is aware of the "indefinite borderline of social action" (Weber 2007: 24) and repeatedly refers to this problem.

3. Of course, this does not imply that these approaches are identical - far from it. In fact, they conceptualize this extrinsic relation in diametrically opposed ways. In an individualist perspective, sociality is the result of coordinated and rational individual actions; in a holist perspective, in contrast, sociality is possible only because of the coercive power of society that forms the primordially asocial subjects.

4. With regard to pragmatism I focus on Cooley and Mead because each of them provided social theory with crucial concepts and systematic theoretical arguments. Also, in contrast to the other pragmatists, they are regarded as 'sociological classics.' This is not to say that the works of Peirce, James or Dewey are irrelevant for sociology. Of course, James' claims regarding the social aspects of personality or Peirce's insistence on the constitutive role of intersubjective processes 
for all semiosis and, hence, for all thinking and research are of crucial importance for pragmatist social thought. Likewise, Dewey not only stated "The Need for Social Psychology" (MW 10) and published an "Introduction to Social Psychology" (the subtitle of Human Nature and Conduct (MW 14)) but was also a decisive influence for both Cooley and Mead. For example, Cooley's perspective on Darwinism was certainly influenced by Dewey (for more details see note 41; also Schubert 1995: 134ff.; Jacobs 2006: 80ff.).

5. As Hans Joas notes in his 1980 study of Mead, "the historical novelty of Mead's theory does not rest on the fact that he proposed simply some conception of intersubjectivity, but rather one that is tenable in light of anthropological knowledge." (Joas 1997 [1980]: 228) This anthropological dimension, however, was hardly considered by sociologists, not even by authors of the Chicago School or Symbolic Interactionism. For the fragmentary reception of pragmatism by the Chicago tradition cf. e.g. Joas (1993: 17f.). Overall, not only the general pragmatist character of Symbolic Interactionism but also the respective influence of Cooley and Mead on it is object of some dispute; cf. e.g. Joas (1993: 14-51); Abbott (1999: 4-33); Scheff 2003; Jacobs 2009.

6. This methodological program became possible because Tomasello has been part of pertinent research institutions. In 1998 he became Director of the "Department of Developmental and Comparative Psychology" at the Max-Planck-Institute for Evolutionary Anthropology in Leipzig. At the same time, he is Co-Director of the Wolfgang Köhler Primate Research Center ("Pongoland"), which is part of the Leipzig Zoo. Before that (starting in 1980), he was Professor at Emory University and Affiliate Scientist for Psychobiology at Yerkes Primate Center (which is part of Emory). A great deal of his research done in Yerkes can be found in his comprehensive work on Primate Cognition (co-authored by Josep Call; cf. Tomasello \& Call 1997).

7. As opposed to pointing, chimpanzees "gesture to one another regularly. Although some of their gestures are relatively inflexible displays invariably elicited by particular environmental events, an important subset are learned by individuals and used flexibly - such things as 'arm raise' to elicit play or 'touch side' to request nursing” (Tomasello 2006: 506).

8. In contrast, "there is no evidence that great apes can do even one step of recursive mind reading [...], which is the cognitive underpinning of all forms of common conceptual ground" (Tomasello 2009b: 72).

9. The concept of 'common ground' Tomasello borrows from the work of Herbert H. Clark (cf. Clark 1996: 92ff.). His cooperation model of communication in general is strongly influenced by diverse authors such as Wittgenstein, Grice, Quine, Searle, Gilbert, Bratman, Tuomela and others (cf. especially Tomasello 2008: 72-108).

10. When the terms 'knowing,' 'guessing,' 'understanding' and the like are used in this paper they do not, of course, imply that the individuals have to be aware of their 'knowledge,' their 'guesses,' their 'understanding' etc. In contrast, what is really intriguing is that by far most of these processes remain basically sub- or unconscious.

11. Tomasello's terminology differs from Peirce's classical semiotic classification (cf. Peirce 1998 [1903]). For instance, according to Tomasello, there can be both symbolic and non-symbolic icons. For Tomasello, "symbols" seem to be defined by "conventionalized representation" mostly of something that is not present. In contrast, the term "iconic" almost always refers to "iconic gestures" which, in turn, is synonymous with "pantomiming" (see, e.g., the subject index of Tomasello 2008: 386). Thus, in Peirce's perspective, Tomasello's concept of the "icon" seems to oscillate between two of his trichotomies - it touches on the nature of the sign itself (qualisign, sinsign, legisign) and at the same time on the relation of the sign and the object (icon, index, symbol). Even though Tomasello refers to Peirce repeatedly, he never (to my knowledge) discusses these semiotic differences.

12. This is why arbitrariness, for Tomasello, is not an absolute characteristic of symbols. Rather, there is a "drift to the arbitrary" (Tomasello 2008: 219-25), i.e., a continuum between iconicity and symbolicity. Here, Tomasello again touches on one of the crucial insights of Peirce's theory 
of signs which - in contrasts to other semiotic approaches - emphasizes the structural interconnection of the different classes of signs. For Peirce, every symbol must at some point be embodied in iconic or indexical signs in order to connect to 'reality' (Peirce 1998 [1903]: 291f.; cf. also Jung 2009: 155, 187, 293).

13. However, note that one cannot be absolutely certain about the exact nature of primate imperative pointing because it is not known whether they understand the cognitive structure of pointing or whether they point to humans because they make desired outcomes happen (cf. Tomasello 2006: 509f.). It seems, however, as though they are just using humans "as a 'social tool"' (Moll \& Tomasello 2007: 643).

14. For this and comparable experiments see Tomasello (2006: 507ff.), and Tomasello (2008: 38ff.). 15. For Tomasello's 'first theory' see e.g. Tomasello \& Rakoczy 2003, and especially Tomasello 1999. In their 1997 Primate Cognition Tomasello and Call discuss the question of whether nonhuman primates understand intentions at length but do not yet answer it conclusively (Tomasello \& Call 1997: 318ff.). - Of course, by speaking of Tomasello's 'first' and 'second' theory, I do not argue that there are two separate approaches. Tomasello would still claim his earlier work to be valid for the most part. Nevertheless, these theoretical modifications need to be highlighted and their implications need to be discussed - especially with regard to Tomasello's earlier work on The Cultural Origins of Human Cognition (1999).

16. To cognize others as 'mental agents' means to understand that they do not only have certain goals and perceptions but also beliefs about the world which may be either right or wrong and which may differ from one's own beliefs. Taking their start from Premack's and Woodruff's claim that chimpanzees have a 'theory of mind,' the two psychologists Wimmer and Perner in a classical paper developed a 'false-belief-task' in order to study the development of the 'theory of mind' in human children. The result was that children develop the ability to understand others as mental agents who may have false beliefs between four and six years of age (cf. Wimmer \& Perner 1983: 126). Yet, because Wimmer's and Perner's "Maxi-test" (just as later modifications of it) presupposes sophisticated linguistic skills, it is not applicable to nonlinguistic beings. This is why Call and Tomasello developed a nonverbal false-belief-task which can be used both with children and apes (cf. Call and Tomasello 1999). The experiments based on this nonverbal design demonstrate "that apes do not have a 'theory of mind' in the sense of understanding the false beliefs of others. This does not mean, however, that apes do not have sophisticated cognitive and social cognitive abilities" (Call \& Tomasello 1999: 393). According to Tomasello's 'first theory,' this lack of understanding necessarily results from their inability to cognize the intentions of others. In his 'second theory,' I suppose that this inability needs to be interpreted as a result of the missing capacity for shared intentionality.

17. In contrast, see Tomasello (1999: 103) for his earlier position on this point.

18. The increasing importance of questions regarding the human motivational structure as well as the stronger focus on 'sharedness' seems to be the main reason why Tomasello shows much interest in the comparative and developmental study of cooperation in the last several years (cf. especially Tomasello 2009b; see also his acceptance speech on the occasion of the 2009 awarding of the Hegel-Prize (2009a)).

19. Not even imperative pointing seems to be purely purposeful. In another experiment, Schwe and Markman demonstrated that two-year-olds were unsatisfied not only when their request was refused but also when it was granted unintentionally. Even in these cases ("You want this (wrong object)? You can't have it but you can have this one (correct object) instead.") the child frequently repeated his/her appeal (cf. Tomasello 2006: 511).

20. The following draws mainly on Tomasello's book The Cultural Origins of Human Cognition which contains the most comprehensive discussion with respect to cultural theory. However, as noted above, this argumentation is based on his 'first theory' of human social cognition. In the following I will reformulate his argument according to his 'second' theory whenever necessary. 
21. There are at least two different forms of sociogenesis. First, a "virtual" form of collaboration that "takes place across historical time" thereby combining different individual innovations. Second, an "actual" form of collaboration that is defined by the simultaneous cooperation of two or more individuals (Tomasello 1999: 41).

22. As noted above, human-raised primates are able to learn by means of imitation (cf. Tomasello et al. 1993).

23. Interestingly, the German title of the book differs slightly from the original one. While the American title speaks of the "Cultural Origins of Human Cognition" the German title 'only' refers to the "Cultural Development of Human Cognition" (Die kulturelle Entwicklung des menschlichen Denkens; cf. Tomasello 2009 [1999]). Ironically, however, the translated German title seems to be more appropriate given Tomasello's main argument: “[S]ocial and cultural processes during ontogeny do not create basic cognitive skills. What they do is turn basic cognitive skills into extremely complex and sophisticated cognitive skills" (Tomasello 1999: 189).

24. For Tomasello's social-pragmatic or "usage-based" theory of language, as well as his criticism of Chomskian linguistics, see Tomasello 1995, and especially Tomasello 2005.

25. Language thus is an extremely powerful form of what Andy Clark (with reference to Vygotsky) calls "external scaffolding": "We may call an action scaffolded to the extent that it relies on some kind of external support. Such support could come from the use of tools, or the knowledge and skills of others; that is to say, scaffolding (as I shall use the term) denotes a broad class of physical, cognitive and social augmentations - augmentations which allow us to achieve some goal which would otherwise be beyond us" (Clark 1998: 163).

26. For the following see Tomasello (1999: 118ff., 170ff.), and especially Tomasello \& Rakoczy 2003. The problem here, again, is that these studies are based in the 'first' theory.

27. Actions learnt by imitation are usually directed to a third object. In contrast, in dialogue, the symbolic acts of others are directed to me. Thus, in order to use them I have to learn to reverse the roles of sender and receiver.

28. The development of children's understanding of the intentional and normative dimension of artifacts is quite similar to their understanding of linguistic symbols (cf. Tomasello \& Rakoczy 2003: 129ff.).

29. According to Tomasello, the bulk of the grammatical complexity of natural languages follows from this need to articulate a specific perspective on a certain situation (Tomasello 1999: 156).

30. Therefore, the use of linguistic symbols allows "children to do things they would not otherwise be able to do in some particular situations, since these symbolic artifacts were created for the purpose of enabling or facilitating certain kinds of cognitive and social interactions" (Tomasello 1999: 95).

31. Tomasello only refers to Mead's most famous work, Mind, Self \& Society. Yet, it must be remembered that this book resulted from the compilation of several notes written by students. Since there is still no critical edition, "the editorial situation of Mead's writings continues to be a disaster" (Joas 1997: xi). In order to avoid editorially questionable references I will whenever possible refer to articles published by Mead himself, especially to the series of articles published between 1909 and 1913 in which he progressed from functional psychology (esp. Mead 1903) to his anthropological social psychology of human interaction and intersubjectivity (Mead 1909, 1910a, 1910b, 1912, 1913).

32. For some interesting comparative remarks on Tomasello and Mead see Jung (2009: 15, 230, 242, 248-52, 376).

33. The concept of the "disciplinary constellation" - which I borrow from Lepenies (1981: xviiff.) - basically implies that the relations a certain discipline maintains with its neighboring/rival/ role model disciplines also affect the development of this very discipline. Of course such a 'constellation' does not determine this development in the strict sense of the term. Yet it defines a certain 'horizon of possibilities.' 
34. Personal conversation. For a short contextualization of Vygotsky's work see Cole; Scribner 1978; for the rediscovery of Vygotsky's work first in the Soviet Union and then in the US from the mid-1950s onward see Bruner 1995. For the relevance of Vygotsky for Tomasello cf. e.g. Tomasello (1999: 20f.); Moll \& Tomasello (2007: 639).

35. For the institutional strategies and the 'boundary work' of the Durkheim Schools cf. e.g. Karady 1981; Besnard 1981.

36. See e.g. Mead 1909; Cooley (2009 [1902/22]: 35-50).

37. For example, Mead demands more exchange between sociology and psychology in order to arrive at a convincing social psychology. Moreover, he regards social psychology and physiological psychology not as opposing but as complementary disciplines (cf. Mead 1909: 402; 407f.).

38. For the general influence of evolutionary theory on American social science see Degler 1991. An overview of the different interpretations of Darwinism in early American sociology (Sumner, Ward, Gray etc.) can be found in Schubert (1995: 112-22). For the influence of evolutionary thought on Cooley see Schubert (1995: Ch. I.3); for Mead see Joas (1997 [1980]: 34ff., 50ff.) and Farr (1996: 54ff.).

39. The basic assumption "that all mental operations can be embedded in the functions of the organism in a non-reductionist manner" (Joas 1997 [1980]: 34) was the starting point of 'functional psychology,' which co-evolved with pragmatism. Dewey's seminal article on "The Reflex Arc Concept in Psychology" (EW 5) can be seen as the founding document of this psychological tradition.

40. For Dewey's and Mead's Hegelian interpretation of Darwin see Thayer (1981: $460 \mathrm{ff}$.), and Joas (1997 [1980]: 54ff.). Also, Bernstein (2010: 92) argues that "Darwin replaced Hegel as a source of inspiration for the organic, dynamic, changing character of life." Because Cooley's early intellectual development revolved around the transcendentalist critique of utilitarianism he was influenced by idealism only indirectly. Yet, Cooley was directly affected by Dewey's interpretation of Darwin since he attended his lectures at the University of Michigan in which Dewey "discussed the Darwinian paradigm, and [...] presented the beginnings of a pragmatic theory of 'social sensorium,' action, and communication" (Schubert 1998: 9).

41. Cf. e.g. Mead (1910b: 177f.; 1912: 402; 1967 [1934]: 14ff., 42ff., 63, 68ff., 162).

42. Thus, to put it simply, Mead agrees with the Darwin in terms of his Origin of Species and The Descent of Man - where Darwin does not only claim the evolution of man out of some simian ancestor but also emphasizes the dramatic consequences of these findings for psychology (1981 [1872]: 48f.) - but disagrees in important ways with Darwin in The Expression of Emotions in Man and the Animal - where he claims that facial and bodily expressions of emotions are just discharges of emotional energy which do not have a function for communicative interaction.

43. That they are, indeed, 'ideal types' in Weber's sense can be seen in the following quote: "Of course there is no sharp line, in this matter of teachability, between man and the other animals. The activities of the latter are not wholly predetermined [...]. On the other side, those activities of man which do not require much adoption, such as the breathing, sucking, and crying of infants [...] are provided for by definite heredity" (Cooley 2009 [1902/22]: 22).

44. In his 1930 obituary for Cooley, Mead strongly criticizes Cooley for his poor phylogenetic account (cf. esp. Mead 2009 [1930]: xxxiiff.).

45. In order to explain the uniquely human form of life we have to presuppose an evolutionary thrust in social cognition towards cooperativeness and sharedness after the human lineage diverged from that of its primate relatives. Consequently, we have a time frame of 5 to 7 million years at the very most. However, "for all but the last 2 million years the human lineage showed no signs of anything other than typical great ape cognitive skills." Furthermore, "the first dramatic signs of species-unique cognitive skills emerged only in the last one-quarter of a million years with modern Homo sapiens" (Tomasello 1999: 2f.). Thus, our problem is "one of time. The 
fact is, there simple has not been enough time to normal processes of biological evolution involving genetic variation and natural selection to have created, one by one, each of the cognitive skills necessary for humans to invent and maintain complex tool-use industries and technologies, complex forms of symbolic communication and representation, and complex social organizations and institutions" (Tomasello 1999: 2).

46. Examples of modular approaches are Chomsky's theory of an innate "language organ" popularized today by Steven Pinker (2000), theories in evolutionary psychology that conceptualize the human mind as a bundle of highly specialized modular tools, that is, as a kind of "Swiss Army knife" (e.g. Tooby \& Cosmides 2005; Buss 1995), or Baron-Cohen's account of the 'theory of mind' and of autism (1995).

47. See Jung (2009: 370): “die Doppelstruktur von Differenzholismus und evolutionärer Kontinuität" (for the concept of the "holism of difference" in general see Jung (2009: 2, 6ff., 54ff., 197ff.).

48. Take, for example, the following quote: "Of course human cognition is in large measure constituted by the kinds of things that appear as chapter headings in traditional Cognitive Psychology textbooks: perception, memory, attention, categorization, and so on. But these are all cognitive processes that human beings share with other primates. My account here simply presupposes them" (Tomasello 1999: 10).

49. For the idea of "dual inheritance theory" see esp. Richerson \& Boyd 2006.

50. The term 'qualitatively' as I use it does not have any normative or ethical connotations. The differences discussed here are - in my view - irrelevant with respect to discussions about speciesism or animal rights.

51. Because of his focus on imaginations, this does not apply to Cooley. Although he touches on the importance of bodily, especially facial, expressions for the development of young children (cf. e.g. Cooley 2009 [1902/22]: 81ff., 97ff.) he does not integrate these observations into a systematic anthropological theory of human communication and intersubjectivity.

52. For criticisms of imitation-theory and the complex motivational and cognitive preconditions of imitation see, for example, Mead (1909: 405ff.; Mead 1922: 160ff.); Cooley (2009 [1902/22]: 51ff.); Tomasello (1999: 26ff.). This does not mean that imitation is not important - far from it. In Tomasello, for example, it is the most important form of cultural learning. At this point, however, all that matters is that imitation is a very demanding process (e.g. Tomasello 1999: 26ff.) and not a relatively simple one which constitutes the anthropological basis of human interaction.

53. For Mead, the difference between social and non-social objects is a decisive step in his argument (e.g. 1909: 403f.; 1910a: 403). In contrast, Cooley only touches on this problem: "By the time a child is a year old the social feeling that at first is indistinguishable from sensuous pleasure has become much specialized upon persons, and from that time onward to call it forth by reciprocation is a chief aim of his life" (2009 [1902/22]: 85).

54. However, despite its promising beginnings McDougall's approach fails to provide a convincing account of self-reflexivity and the self (Mead 1908: 389).

55. For example, in 1909 Mead argues: "If self-conscious conduct arises out of controlled and organized impulse, and impulses arise out of social instincts, and the responses to these social stimulations become stimuli to corresponding social acts on the part of others, it is evident that human conduct was from the beginning of its development in a social medium" (Mead 1909: 403f.).

56. This is, of course, the toe-hold to Cooley's theory of the social self that finds its expression in the well-known concept of the "looking-glass self" (Cooley 2009 [1902/22]: 184f.).

57. This shortcoming can be recognized by the mere fact that the concept of "sociability" is hardly mentioned after Ch. III of Human Nature and the Social Order. Conversely, the term "sympathy" (in the sense of "understanding") gains crucial importance only from Ch. IV on. 


\section{ABSTRACTS}

The relationship between action and sociality is one of the fundamental problems in social theory and philosophy. In this paper I strive to contribute to an action theoretical approach that conceives of individual action and sociality as intrinsically related. I will do so by drawing on two distinct strands of cultural and social theory: the sociological pragmatism of Charles Horton Cooley and George Herbert Mead, and the cognitive cultural psychology of Michael Tomasello. Since the work of Tomasello is - at least in detail - relatively unknown to philosophers or social scientists, the primary focus will be on his seminal studies in comparative and developmental cognitive psychology. By means of a detailed analysis I will delineate a cognitive, motivational and cultural dimension of the sociality of action in Tomasello. The results of this discussion will then be compared with the central tenets of sociological pragmatism. In the end, it will become clear why cognitive scientists like Tomasello can help us to reformulate pragmatist social theory against the background of recent findings in the human sciences. By doing this, we can remain true to the transdisciplinary approach of pragmatist thought that has long been neglected in social theory. Conversely, such a comparison may reveal some of the limits of Tomasello's account with regard to social theory.

\section{AUTHOR}

FRITHJOF NUNGESSER

University of Graz

frithjof.nungesser[at]uni-graz.at 